\title{
Survey of Required Infrastructure for Web-Based Management of Civil Projects by Introducing a Suggestive Model
}

\author{
Amir Reza Estakhrian Haghighi and Sina Safaee
}

\begin{abstract}
In present era, we see information systems establishment in advanced society and everyday information exchange rate becomes more and more .This process cause to form fundamental substructure based on technology in these society. It instruments have been consisted of computer sciences, communications and Network in two frame of software and hardware: today, It has been stated extensive and various applications from them in different contexts and changed into strategic role in organizations. One project needs many information which it can be easily accessed by information technology, so that it can be devoted necessary resources to perform project based on it .Therefore, It tools can have important role to change in management function in one project' and deliver novel definition about management as title of electronic management or virtual one which is one management procedure in which it is substituted by face-to-face communications with electronic and virtual communications.

Since developmental projects management is one of more expensive managements In countries, thus technological tools can have more important role to change in management procedure from traditional space to electronic space by purpose of optimization of project management aims which is decrease of expense increase of speed and quality improvement .In this article, it is tried to give one suggestion model to enforce comprehensive electronic management in one developmental project. It is also studied necessary substructure to allow for it tools application in project management process.
\end{abstract}

Index Terms-Electronic management, virtual management project management, Internet station, substructure.

\section{INTRODUCTION}

In this article, it will be suggested a flow- chart about one web-based Management of one developmental project as a sample in order to study essential substructure to enforce web-based management in one developmental project [1].

then in is introduced effective elements in management process in one project, and subsequent it will be studied necessary sub-structures to in force web-based Management virtual management in one developmental project in respect to Proposal chat and introduced effective elements [2].

\section{A. Proposal Chart in Direction of Pilot Project Electronic Management}

Proposal Chart is presented about pilot developmental

Manuscript received February 4, 2013; revised June 18, 2013.

Amir Reza Estakhrian Haghighi is with the Dept. of Computer and IT Islamic Azad University, Sepidan Branch, Shiraz, Co 7194785417 Iran (e-mail: amirestakhrian@ut.ac.ir).

Sina Safaee is with the Dept. of ISC Research Affairs Islamic World Science Citation Center Shiraz, Co 7194785415 Iran (e-mail Sina.safaee@gmail.com). project in this article in order to enforce it via web bed and by virtual procedure as follow [3]. As it is known from figure, first rating of organization in this project is for project director and second rating is for workshop supervisor .It is worth to point that in Fig. 1 organizational communications which are drop to lower rank from one organizational rank as several parallel lines (like relation between performance engineer and technician)' show that organizational lower rank exist as number of more than one unit .which have common and similar duties and it is supervised under organizational higher rank [4].

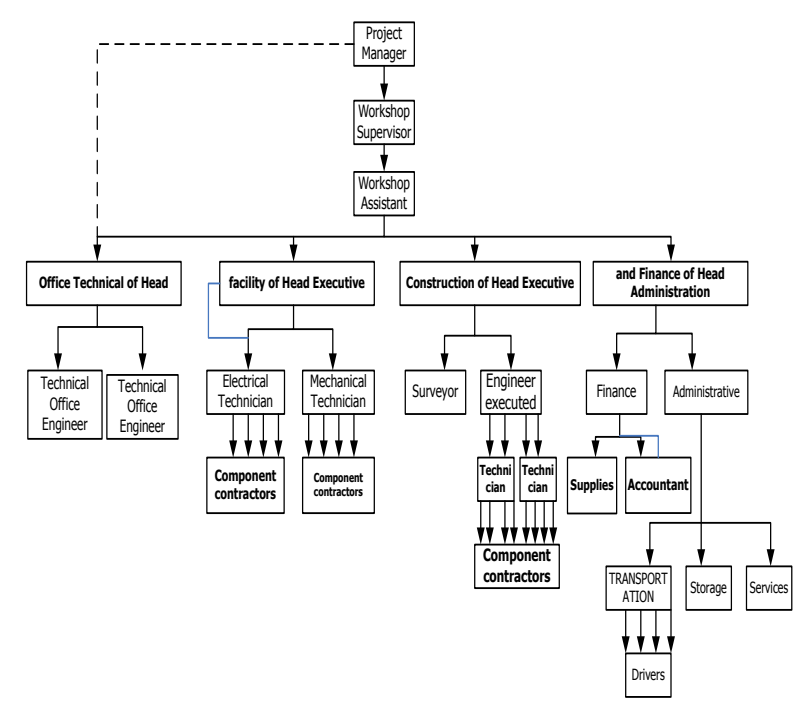

Fig. 1. Pilot project chart.

It is root to note in considered pilot project to this research, project manager use design consultation to optimize output, and also it is assumed that supervisor system is enforced by two machines located in project and established in central office of project management which is out of workshop place. So, it is assured that it is required some elements such as consulter; performer, contractor, contractor, in order to perform this developmental project [5].

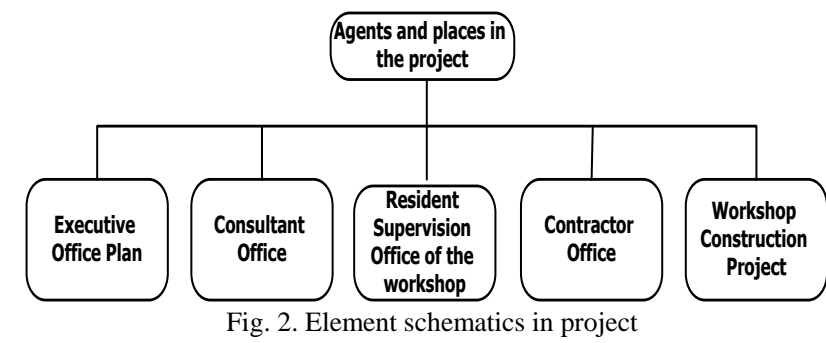

How to communicate between project members in electronic environment will be like Star -shape as fallow. As 
you see in Fig. 3 in electronic environment all project factors such as project manager,workshop supervisor,technical office supervisor,accountant, technicians, Provision responsible and ...are communicating and interacting together via central electronic management website with predefined access levels.

In another word in fact central node is the same as central site which it will communicate with all elements as one - by one and directly [6].

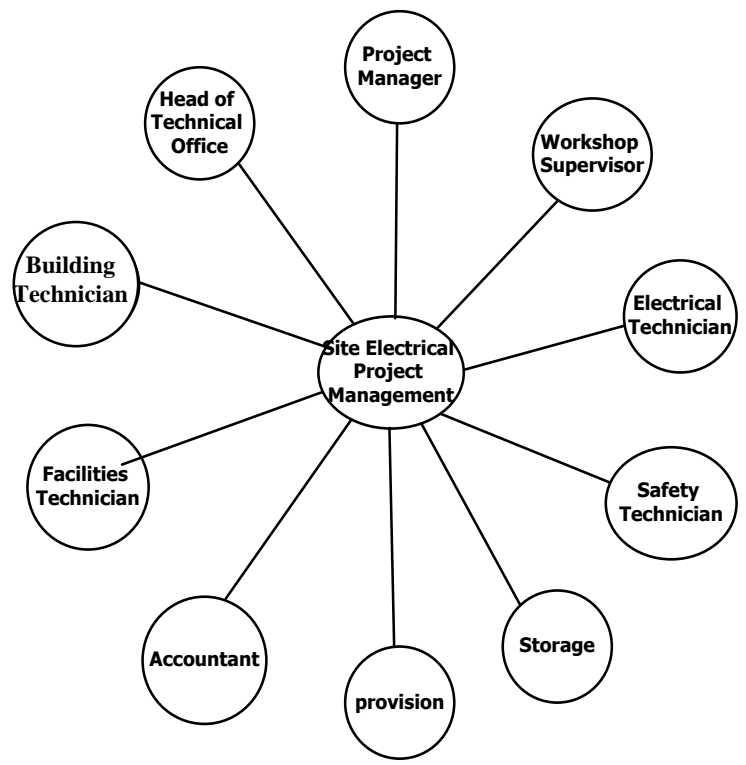

Fig. 3. Profile of project communication in electronic environment.

\section{B. Pre-Requisites of Electronic Procedure Enforcement}

ecnis in this research project system and sub systems ,which are included operational trends are modeled by electronic procedure [7]. So it is necessary that it is first studied necessary preparations and pre - requisites to enforce novel method of management Via IT tools. For this reason it is required follow instruments in order to make electronic in project management environment in first step [8].

- Integrated and comprehensive internet database

- Possibility of suitable communication and connection to internet.

- Communicating instruments with internet.

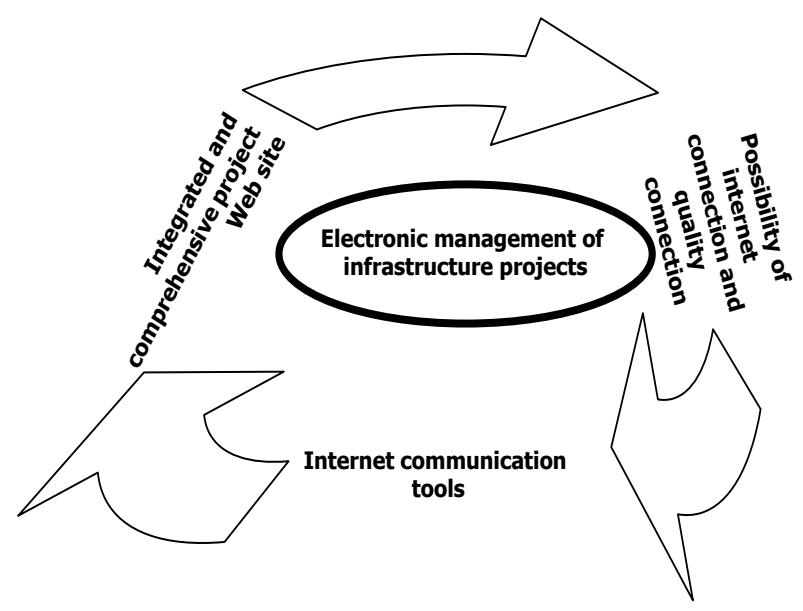

Fig. 4. Pre - requisite of electronic management.

In Fig. 4, we explain more about each of these instruments.

\section{PROJECT COMPREHENSIVE AND INTEGRATED INTERNET SITE}

In such internet site which is required to manage one developmental project it must be considered several items [9]. These are included:

- Each person definition related to project in internet site by use of one unique user name and one password which by entering these two features to project internet site " this site recognizes person and while to allow enter" shows all accessible parts to him.

- Definition of all accessible levels to available data in site which is different depend on each person or client; this becomes possible $\mathrm{Via}$ devote persons username to different parts of site.

- Determination of all performing procedures in internet site, so that these smart trends conduct required communications from person to person. By this definition, besides; these are very quick navigation possibility about communications and each process follow-up in this internet site, so the communications accomplish to purpose by their default definitions with extra rate. The project manager can remove, add and change in these procedures.

- Defined strong and confident communication of this internet site with contract party bank's internet site; so that it can be discussed financial and fee receives easily. Definition all required work parts as numbered in internet site databases, in which it is available All project performance components just as existing project maps such as Buildings, walls, door and windows, patter of electricity, water, gas and Telephone channel and all another parts with comprehensive coding have Been coded .By this, project electronic management comprehensive software Identify each small part by its related number; so that it can easily identified and marketed in reporting and registering future information.

- Definition of all kinds of materials with a very comprehensive coding in site Databases until request, purchase and storing steps for site to utilize each Number item. It is worth to note that all internet site characteristics such as mentioned cases, are changeable and editable via project manager so that this site can match itself with real existing conditions, optimally.

\section{Possibility OF Suitable COMMUNICATIONS AND CONNECTION TO INTERNET}

This communication with internet must be independent of place for People in project by use of wireless internet technology, so the responsible Persons can inform existing condition in project internet site by refer to it while it wouldn't be disconnected internet communications with individuals [10]. The Required communications for this project level must be rather strong so that it doesn't make disorder in work procedure and data exchange with internet site. It is suggested to sue $\mathrm{Wi}-\mathrm{Fi}$ technology to cover internet in project environment. Meanwhile, all organizations and unit in projects must have easy communications with Project internet site. There are included.

1) project development workshop; 
2) central contractor office ;

3) supervision system office in workshop.

4) consultation central office;

5) central designer office,

And are other related united to project.

\section{COMMUNICATION TOOLS WITH INTERNET}

There are several tools and methods to communicate with internet; but based on manager's experiences who manage their project as electronic; it was been pointed In second chapter That contains some cases such as personal computers which are used at home and workplace. Mobile computers are always accompanied by person and are connected to internet Via itself [11]. There are personal digital assistant systems (PDA) which can be next to person because of their small size and do their routine office works, meanwhile they it is easily connected to internet at last, mobile phone besides use of ability. To send short message which it reaches to destination of the same time, have Possibility to send electronic mails and even connection to internet and search within it via use of WAP protocol.

\section{CONCLUSION}

Today, it has been possible to enforce management new procedures in projects typically developmental projects in respect to develop increasingly it instruments.

In order to realize web-based management method which is called virtual Management needs sub-structure to enforce this new management Procedure which the most important necessary elements in this sub-structure are comprehensive and integrated internet site, the possibility of communication and suitable connection to internet and communicating instruments to internet.

By utilizing patterns to manage electronic, one developmental project can see significant decrease in expenses, increase in speed and Improvement of final quality of project in provisions, communications, Quality and expense of one project domains.

\section{REFERENCES}

[1] F. Belanger, W. Manheim, M. B. Jordan et al. "Aligning IS research and practice: a research agenda for virtual work," Information Resources Management Journal, vol. 15, no. 3, pp. 48-70, Jan. 2002.

[2] B. Gordon, "Working together, apart the web as project infrastructure," Interanet Journal, July 2007.

[3] K. Jonathan, "Project management basics [electronic resource]: using technology to collaborate more effectively and bring projects to completion faster/Jonathan Knowles," PMI Global Congress--Asia Pacific, Bangkok, Thailand: Project Management Institut, May 2006.

[4] D. Khazanchi and I. Zigurs, Patterns of Effective Management of Virtual Projects: an Exploratory Study, July 2005.

[5] M. M. Medina and B. Bengiamin. (n.d.). Managing Virtual Work: Integrating Reflection and Action through Appropriate Software Support. Retrieved March 25, 2008.

[6] Virtual-Organization. [Online]. Avaliable: http://www.virtual-organization.net/files/articles/Manheim_Watson_ US.pdf

[7] M. Abbe, "On the Theory of Virtual Organization," Sys. Res Beh. Sci. vol. 14 , no. 4, pp. 373-376, 2009.

[8] A. Pluss, C. Huber, G. Sung, and B. Sari, Virtual Porject Management-Concept, Training and Tools, July 2006.

[9] Y. Pollalis and N. Dimitriou, "Knowledge management in virtual enterprises: a systemic multi-methodology towards the strategic use of information," International Journal of Information Management, pp. 305-321, September 2009.

[10] Project Management Body of Knowledge (PMBOK), Pennsylvania: Project Management Institue, 2004.

[11] Y. P. Shao and S. Liao, A New Organizational Model: Implication on Virtual Organizations, May 1996.

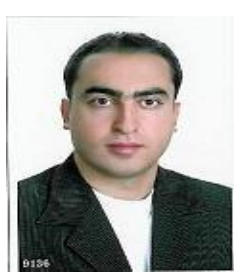

Amir Reza Estakhrian Haghighi was born on May 18, 1978 in Shiraz, Iran. He is a Ph.D candidate of Multi-Media Management. He obstained the B.Sc. in Electronic Eng. And M.Sc. in IT Eng. He is a full time faculty member of IA-University. His research interests include internet, digital media, e-marketing, web design.

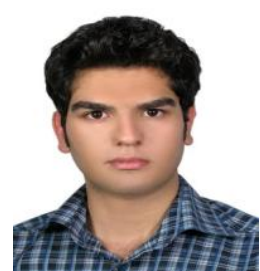

Sina Safaee was born on August 7, 1987 in Shiraz, Iran. He obtained the B.Sc. and M.Sc. in Industrial Management at Dept. of ISC Research Affairs Islamic World Science Citation Center. His research interests are e-marketing, industrial management, IT, animation. 